\title{
Metabolic syndrome in children and adolescents
}

\author{
Dania Al-Hamad, Vandana Raman \\ Division of Pediatric Endocrinology and Diabetes, University of Utah, Salt Lake City, UT, USA \\ Contributions: (I) Conception and design: All authors; (II) Administrative support: None; (III) Provision of study materials or patients: None; (IV) \\ Collection and assembly of data: None; (V) Data analysis and interpretation: None; (VI) Manuscript writing: All authors; (VII) Final approval of \\ manuscript: All authors. \\ Correspondence to: Dania Al-Hamad, MD. Division of Pediatric Endocrinology and Diabetes, University of Utah, Salt Lake City, UT, USA. \\ Email: Dania.al-hamad@hsc.utah.edu.
}

\begin{abstract}
Prevalence of metabolic syndrome in children and adolescents is increasing, in parallel with the increasing trends in obesity rates. Varying definitions of this syndrome have hindered the development of a consensus for the diagnostic criteria in the pediatric population. While pathogenesis of metabolic syndrome is not completely understood, insulin resistance and subsequent inflammation are thought to be among its main mechanistic underpinnings. Overweight and obesity are cardinal features, along with abnormal glucose metabolism, dyslipidemia, and hypertension. Other disorders associated with metabolic syndrome include fatty liver, polycystic ovarian syndrome (PCOS), and pro-inflammatory states. Prevention and management of this condition can be accomplished with lifestyle modifications, behavioral interventions, pharmacological and surgical interventions as needed.
\end{abstract}

Keywords: Metabolic syndrome; pediatrics; obesity

Submitted Aug 17, 2017. Accepted for publication Sep 26, 2017.

doi: $10.21037 /$ tp.2017.10.02

View this article at: http://dx.doi.org/10.21037/tp.2017.10.02

\section{Introduction}

As the proportion of the population with obesity continues to rise, the prevalence of metabolic syndrome is increasing in both children and adolescents $(1,2)$. Children with metabolic syndrome have an increased risk of metabolic syndrome as adults, and possibly an increased risk of type 2 diabetes mellitus (T2DM) and cardiovascular disease (CVD) $(3,4)$. Thus, it has become crucial to gain a better understanding of its pathophysiology, risk factors and to identify strategies for management of metabolic syndrome in childhood (5).

Historically, metabolic syndrome started as a concept, rather than a diagnosis and has been described using several other names throughout the years (6). It was initially described in the 1920s, when Kylin, a Swedish physician, demonstrated the association of hypertension, hyperglycemia and gout (7). Later in 1947, Vague showed that central obesity was associated with the metabolic abnormalities found in CVD and T2DM (8). Avogaro and
Crepaldi described this syndrome in 1965 and that it is comprised of hypertension, hyperglycemia, and obesity (9). Reaven in 1988 described a cluster of risk factors for diabetes and CVD and named it "syndrome X". He was the first to describe insulin resistance and its association with metabolic syndrome (10). In 1989, Kaplan renamed the syndrome "the deadly quartet" for the combination of upper body obesity, glucose intolerance, hypertriglyceridemia, and hypertension (11), and in 1992, it was again renamed "the insulin resistance syndrome" (12). In 2001, the National Cholesterol Education Program (NCEP) coined the term "metabolic syndrome", as the presence of 3 out of 5 risk factors: central obesity, hyperglycemia, hypertriglyceridemia, high-density lipoprotein (HDL) and hypertension. With the increase in obesity rates, investigators began associating obesity in children with disorders such as metabolic syndrome that were previously mostly seen in adults. In the last many years, research in this area has significantly increased. Yet, there remain many unanswered questions regarding the definition of metabolic 
Table 1 Adult definitions

\begin{tabular}{|c|c|c|c|}
\hline Variables & WHO & NHLBI/NCEP III & IDF definition ages $16+$ (adult and pediatric) \\
\hline Central obesity & $\begin{array}{l}\text { Men: waist to hip ratio: }>0.90 \text {; } \\
\text { women: waist to hip ratio }>0.85 \\
\text { and/or } \mathrm{BMI}>30 \mathrm{~kg} / \mathrm{m}^{2}\end{array}$ & $\begin{array}{l}\text { Men: } W C \geq 102 \mathrm{~cm} \text {; women: } \\
W C \geq 88 \mathrm{~cm}\end{array}$ & Men: $W C \geq 94 \mathrm{~cm}$; women: $W C \geq 80 \mathrm{~cm}$ \\
\hline Hypertension & $\begin{array}{l}\text { SBP } \geq 140 \mathrm{mmHg} \text { or DBP } \\
\geq 90 \mathrm{mmHg} \text { or treatment with } \\
\text { anti-hypertensive medication }\end{array}$ & $\begin{array}{l}\mathrm{SBP} \geq 130 \mathrm{mmHg} \text { or DBP } \\
\geq 85 \mathrm{mmHg} \text { or treatment with } \\
\text { anti-hypertensive medication }\end{array}$ & $\begin{array}{l}\mathrm{SBP} \geq 130 \mathrm{mmHg} \text { or } \mathrm{DBP} \geq 85 \mathrm{mmHg} \text { or } \\
\text { treatment with anti-hypertensive medication }\end{array}$ \\
\hline Hypertriglyceridemia & $\mathrm{TG} \geq 150 \mathrm{mg} / \mathrm{dL}$ & $\begin{array}{l}\mathrm{TG} \geq 150 \mathrm{mg} / \mathrm{dL} \text { or on treatment } \\
\text { for high } \mathrm{TG}\end{array}$ & $\mathrm{TG} \geq 150 \mathrm{mg} / \mathrm{dL}$ or on treatment for high $\mathrm{TG}$ \\
\hline Impaired glucose & As noted above & $\begin{array}{l}\mathrm{FPG} \geq 100 \mathrm{mg} / \mathrm{dL} \text { or known } \\
\text { T2DM }\end{array}$ & FPG $\geq 100 \mathrm{mg} / \mathrm{dL}$ or known T2DM \\
\hline Urinary albumin & $\begin{array}{l}\text { Urinary albumin excretion } \\
\geq 20 \mathrm{mcg} / \mathrm{min} \text { or albumin/ } \\
\text { creatinine ratio } \geq 30 \mathrm{mg} / \mathrm{g}\end{array}$ & - & - \\
\hline
\end{tabular}

WC, waist circumference; SBP, systolic blood pressure; DBP, diastolic blood pressure; TG, triglyceride; HDL, high density lipoprotein; FPG, fasting plasma glucose; WHO, World Health Organization; NHLBI, National Heart, Lung and Blood Institute; NCEP, National Cholesterol Education Program; IDF, International Diabetes Foundation; T2DM, type 2 diabetes mellitus.

syndrome and implications for clinical care in pediatrics (13).

\section{Definition}

Metabolic syndrome is defined by a constellation of physiological, biochemical, clinical, and metabolic factors that directly increase the risk of atherosclerosis, T2DM, and all-cause mortality (6). Definitions of metabolic syndrome in adults have been published by many organizations including the World Health Organization (WHO), NCEP III, International Diabetes Foundation (IDF) and the National Heart, Lung and Blood Institute (NHLBI). Due to varying definitions, and an attempt to achieve some consensus, a statement was made by the Joint Task Force. According to this statement, the proposed criteria for metabolic syndrome in adults should include 3 of the following 5 criteria $(14,15)$ :

(I) Elevated waist circumference based on population and country-specific definitions;

(II) Systolic blood pressure (BP) of $130 \mathrm{mmHg}$ or more and/or diastolic BP of $85 \mathrm{mmHg}$ or more or on treatment for hypertension;

(III) Fasting blood glucose of $100 \mathrm{mg} / \mathrm{dL}$ or more or on treatment for hyperglycemia;

(IV) Triglycerides of $150 \mathrm{mg} / \mathrm{dL}$ or more or on treatment for elevated triglycerides;

(V) HDL cholesterol less than $40 \mathrm{mg} / \mathrm{dL}$ in males and less than $50 \mathrm{mg} / \mathrm{dL}$ in females or on treatment for reduction of HDL cholesterol.

Currently, there are no consensus guidelines or diagnostic criteria for metabolic syndrome in the pediatric population (16). In fact, more than 40 definitions have been reported (17). Though the definitions have many similarities, there are important differences between them with respect to cut-off points for various parameters. These are summarized in Tables 1 and $2(13,14,18-21)$.

\section{Epidemiology}

It is difficult to estimate the prevalence of metabolic syndrome in children because many different criteria have been used in its multiple definitions. Various publications 
Table 2 Pediatrics definitions

\begin{tabular}{llll}
\hline Variables & IDF definition age $<10$ years & IDF definition ages $10-16$ years & Cook et al. \\
\hline Defining criteria & $\begin{array}{l}\text { Cannot be diagnosed in } \\
\text { the age group }\end{array}$ & Central obesity plus at least 2 out of 4 criteria & $\geq 3$ criteria \\
Central obesity & & $\mathrm{WC} \geq 90^{\text {th }}$ percentile or adult cut-off if lower & WC $\geq 90^{\text {th }}$ percentile \\
Hypertension & $\mathrm{SBP} \geq 130 \mathrm{mmHg}$ or DBP $\geq 85 \mathrm{mmHg}$ or treatment & $\mathrm{BP} \geq 90^{\text {th }}$ percentile \\
& with anti-hypertensive medication & $\mathrm{TG} \geq 110 \mathrm{mg} / \mathrm{dL}$ \\
Hypertriglyceridemia & $\mathrm{TG} \geq 150 \mathrm{mg} / \mathrm{dL}$ & $\mathrm{HDL} \leq 40 \mathrm{mg} / \mathrm{dL}$ \\
Low HDL & $\mathrm{HDL}<40 \mathrm{mg} / \mathrm{dL}$ & $\mathrm{FPG} \geq 110 \mathrm{mg} / \mathrm{dL}$ \\
Impaired glucose & $\mathrm{FPG} \geq 100 \mathrm{mg} / \mathrm{dL}$ or $\mathrm{known} \mathrm{T2DM}$ &
\end{tabular}

have noticed prevalence numbers ranging from $0.2 \%$ to $38.9 \%$ (22). In a systematic review of 85 studies in children, the median prevalence of metabolic syndrome in whole populations was $3.3 \%$ (range $0-19.2 \%$ ), in overweight children was $11.9 \%$ (range $2.8-29.3 \%$ ), and in obese populations was $29.2 \%$ (range 10-66\%). For non-obese, non-overweight populations, the range was $0-1 \%(23)$. Close to $90 \%$ of obese children and adolescents have at least one feature of the metabolic syndrome (18). The prevalence is also higher in Hispanics compared to Caucasian, or African American population (14,24). A clustering of risk factors associated with metabolic syndrome has been demonstrated in certain adult populations, including East Asians, Asian Indians, Native Americans, Japanese Americans and Hispanics $(25,26)$.

\section{Pathogenesis}

Although the pathogenesis of metabolic syndrome is not completely understood, recent data suggest that interaction between obesity, insulin resistance and inflammation play a key-role in its development (14). It is suggested that accumulation of free fatty acids in the liver, adipocytes, skeletal muscles and the pancreas in the setting of obesity leads to impaired insulin signaling and subsequent insulin resistance. Insulin resistance in the liver leads to decrease in its effect on suppression of glucose production (27). Additionally, hyperinsulinemia causes an increase in the transcription of genes for lipogenic enzymes in the liver, which leads to increased production of triglycerides. The increase in free fatty acids delivery to the liver is thought to result in hepatic insensitivity to the inhibitory effects of insulin on very low density lipoprotein (VLDL) secretion and overproduction of triglyceride-rich VLDL particles (28). Elevated BP in metabolic syndrome is thought to be secondary to hyperinsulinemia via mechanisms such as sympathetic nervous system activity, renal sodium retention and smooth muscle growth (14). Insulin has a vasodilatory effect on the endothelium secondary to the production of nitric oxide (a potent vasodilator) (29). Endothelial dysfunction and disturbed vasodilatory response frequently occur secondary to insulin resistance (30). It is believed that inflammatory cytokines release from dysfunctional adipocytes, such as, monocyte chemoattractant protein-1, and tumor necrosis factor-alpha, promotes macrophages migration to those adipose tissues and further increase cytokine production (14). Additionally, a decrease in adiponectin level seen in obesity can result in more inflammatory process in the adipose tissues $(14,31)$.

\section{Clinical features}

Clinical features seen in metabolic syndrome are:

(I) Obesity: this is an essential component of the metabolic syndrome and the development of T2DM and CVD (14). This is evident by the strong association between the degree of obesity and the prevalence of metabolic syndrome and insulin resistance after adjusting for race and ethnicity as described by Weiss and colleagues (31). Obesity is diagnosed based on body mass index (BMI), with those with a $\mathrm{BMI} \geq 95^{\text {th }}$ percentile for gender and age are considered obese (14). Overweight status is defined as a BMI of $\geq 85^{\text {th }}$ percentile and $<95^{\text {th }}$ percentile in children. Additionally, visceral fat accumulation, independent of the degree of obesity, is strongly associated with both childhood metabolic syndrome and CVD later in life $(32,33)$. Visceral adiposity can be estimated using waist circumference, waist to hip ratio and 
magnetic resonance imaging (14). While waist circumference is considered indicative of visceral adiposity (34), the lack of pediatric reference range data precludes its use in the routine evaluation for childhood obesity. Alternatively, waist to height ratio is used in children. A ratio of 0.6 or more is indicative of increased risk for metabolic syndrome and CVD (35). It is believed that the incorporation of waist measures can improve cardiometabolic risk stratification among children suggesting that waist measures should be considered in routine pediatric screening (35).

(II) Dyslipidemia: an increased triglyceride to HDL ratio could be used as a marker for elevated lowdensity lipoprotein (LDL) in adolescents. A ratio of 3 or more, is indicative of more small-dense LDL particles and is associated with a higher risk for CVD given the atherogenic effect of this LDL (36).

(III) Hypertension: an important component of the metabolic syndrome and a modifiable risk factor for CVD.

(IV) Glucose intolerance and T2DM: insulin resistance is described in obesity. Glucose intolerance (impaired fasting glucose or impaired glucose tolerance) and T2DM develop as a result of deterioration of $\beta$-cell function and subsequent reduction in insulin secretion capacity. Impaired fasting glucose is defined as fasting blood glucose of $\geq 100$ and $<126 \mathrm{mg} / \mathrm{dL}$ and impaired glucose tolerance is diagnosed if blood glucose is $\geq 140$ and $<200 \mathrm{mg} / \mathrm{dL}$ at the 2 -h mark of the oral glucose tolerance test (OGTT). According to the American Diabetes Association (ADA), diabetes is diagnosed when at least one of the following criteria are met: (i) hemoglobin A1C of $6.5 \%$ or more; (ii) fasting blood glucose of $126 \mathrm{mg} / \mathrm{dL}$ or more; (iii) blood glucose at $2 \mathrm{~h}$ post OGTT of $200 \mathrm{mg} / \mathrm{dL}$ or more; (iv) random blood glucose of $200 \mathrm{mg} / \mathrm{dL}$ or more with classic symptoms of hyperglycemia or hyperglycemic crisis. In the absence of unequivocal hyperglycemia, results should be confirmed by repeat testing (37). Progression from insulin resistance towards glucose intolerance and or $\mathrm{T} 2 \mathrm{DM}$ is variable among individuals. Hence, routine monitoring for the development of overt T2DM symptoms is essential.

(V) Nonalcoholic fatty liver disease (NAFLD): NAFLD is the most common cause of liver disease in children with a recent rise in its incidence that correlates with the increase in obesity prevalence among children and adolescents (38). Liver involvement varies in severity from asymptomatic steatosis to nonalcoholic steatohepatitis (NASH) with inflammation to advanced fibrosis with cirrhosis, and can lead to hepatocellular carcinoma. Intrahepatic fat accumulation is thought to be secondary to insulin resistance, which in turn leads to macrovascular hepatic steatosis (38). Diagnosis is challenging as a liver biopsy is required. However, noninvasive measurement of biochemical markers and ultrasonographic imaging of the liver may be helpful (38).

(VI) Polycystic ovarian syndrome (PCOS): PCOS is characterized by hyperandrogenism and is commonly associated with obesity and insulin resistance in adolescent females. However, PCOS is an independent risk factor for metabolic syndrome irrespective of the weight status or the presence of insulin resistance (39). Females with PCOS should be monitored and screened frequently for development of evidence of metabolic syndrome (14).

(VII) Inflammatory markers: obesity is associated with pro-inflammatory state secondary to the increased production of inflammatory cytokines by the visceral adipocytes. Inflammatory markers include interleukin-6, tumor necrosis factor-alpha, and C-reactive protein (CRP) $(31,40)$. CRP is used for CVD risk stratification in adults. In children, CRP is associated with insulin resistance in overweight and obese children and adolescents, although the exact relationship between CRP and metabolic syndrome is not entirely clear (41).

\section{Screening}

Clinicians should identify obese and overweight children who are at risk for T2DM and CVD. These children should be screened for behavioral and medical risks, including persistent obesity, as well as its associated co-morbidities (42). Presence of parental obesity is a major risk factor for childhood obesity that should be included in the screening evaluation (42).

History and physical examination constitute the first step in screening for comorbidities. Clinicians should inquire about signs and symptoms for associated comorbidities such as obstructive sleep apnea which may be confirmed 
with polysomnography, PCOS, and liver disease (42). Serum alanine aminotransferase (ALT) and aspartate aminotransferase (AST) levels, are reasonably good screening tests for fatty liver disease. Referral to a pediatric hepatologist is recommended for levels that exceed twice the upper limit of normal (42). It is suggested that screening for liver disease be performed bi-annually starting at the age of 10 years for children with obesity or for those who are overweight with other risk factors $(42,43)$.

Screening for T2DM is recommended in overweight and obese children and adolescents with any two of the following risk factors: (I) Family history of T2DM in first or second degree relatives; (II) at risk race or ethnicity (Native American, African American, Latino, Asian American, and Pacific Islander); (III) signs of insulin resistance or associated conditions such as acanthosis nigricans, hypertension, dyslipidemia, PCOS, or a history of being born small for gestational age; and (IV) maternal history of diabetes or gestational diabetes during the child's gestation (37). The ADA recommends that screening be started at age 10 years or at the onset of puberty whichever occurs sooner, and to be repeated every 3 years (37). OGTT is the gold standard for diagnosis of diabetes. Fasting glucose and/or hemoglobin A1C may be helpful in identifying patients at higher risk (37).

BP should be obtained annually at all health maintenance visits starting at age 3 years and compared to reference ranges from tables issued by the NHLBI (44). Finally, routine screening for dyslipidemia with universal lipid screening between age 9 and 11 years with non-fasting nonHDL lipid profile is recommended for all children. Obesity is considered a moderate to high level risk factor for which screening with fasting lipid profile is recommended to be obtained for children $2-8$ years of age (44). Lipid profile should be repeated between age 12 and 16 years in overweight adolescents per the NHLBI recommendations. Dietary versus medical intervention should be pursued based on the level of abnormality and presence of other defined risk factors and high risk conditions (44).

\section{Prevention and treatment of metabolic syndrome}

\section{Prevention}

The primary goal in prevention of pediatric obesity is promoting life style modifications such as healthy diet and increased physical activity. Life style modifications include adopting healthy eating habits by increasing intake of fruits and vegetables, more fiber and less dietary fat in addition to avoiding carbonated drinks, refined carbohydrates, high fructose corn syrup, high sodium, and processed food (45-47). Fruit juice intake should be limited to 4-6 ounces per day for children 6 month to 6 years of age and 8-12 ounces daily for older children according the American Academy of Pediatrics (AAP). Daily fruit juice intake is found to be associated with increased risk for developing overweight status and obesity especially in early preschool years $(48,49)$. Fruit juice should be replaced with whole fruits for additional nutritional value. Incorporation of at least $20 \mathrm{~min}$ of vigorous short bursts of physical activity 1 day, 3 to 5 days per week can improve metabolic measures in children and adolescents and may prevent obesity (47). A meta-analysis conducted by Kamath and colleagues found that life style modifications had a positive effect on reducing sedentary behavior in long-term trials and reduced unhealthy dietary habits. Those changes were more effective when directed toward children compared to adolescents (50). Additional life style modifications that can reduce the likelihood of developing obesity include: adopting healthy sleep habits; limiting discretionary screen time; involving the whole family and community in prevention efforts; using school-based programs and community engagement in prevention of pediatric obesity $(45,47)$. A multidisciplinary approach, which includes dieticians, mental health practitioners, providers, and nurses is very helpful in obesity prevention. (47).

\section{Treatment}

In general, treatment of childhood metabolic syndrome currently focuses on several areas that include weight reduction via dietary intervention, increased physical activity, life style modifications, and management of various disease-specific components (14). Other available options to manage obesity include behavioral intervention, pharmacological therapies and bariatric surgery.

\section{Lifestyle modifications and behavioral treatment}

It is recommended that providers assess patients and families for readiness to change. This will facilitate incorporation of intervention. Programs involving the whole family in lifestyle intervention programs were found to have positive results in $\mathrm{BMI}$ reduction compared to those directed at the child alone $(51,52)$. Weight reduction in obese children and adolescents following comprehensive nonsurgical interventions including diet, physical activity, education, and behavioral therapy were found to be associated with improvements in several metabolic parameters such as lipid profile indices and BP (53). 
Obese children and adolescents should be screened for depression and other mood disorders given the increased risk for such mental health problems. Support and referral to available behavioral health resources for those in need is essential (14). Formal maintenance programs are helpful in maintaining achieved weight loss (54).

\section{Dietary intervention}

Dietary interventions recommended in the recent Endocrine Society guidelines based on the AAP and the US Department of Agriculture include: elimination of sugar sweetened beverages; decrease consumption of fast food; less added table sugar; avoidance of high fructose corn syrup; less high sodium processed food; and less saturated dietary fat in adolescents and children older than 2 years of age. Further, consumption of whole fruits, vegetables and dietary fiber is encouraged in addition to portion control education, enhancing food labeling, and encouraging eating regular meals to avoid grazing (47). A recent meta-analysis conducted by Gow et al. (55) suggests that primary goal in dietary intervention programs should focus on reduced total energy intake based on the observation that a reduced energy diet, irrespective of the macronutrient distribution, was successful in improving weight status in overweight and obese children and adolescents. It is essential that dietary interventions and calorie reduction in children and adolescents are supervised by an experienced dietician in growing children's needs (47).

\section{Physical activity}

It is recognized that inactivity can lead to lower insulin sensitivity in skeletal muscle and this can be reversed with increased physical activity (14). A minimum of $20 \mathrm{~min}$ of moderate to vigorous physical activity daily, with a goal of $60 \mathrm{~min}$ daily is recommended in the context of a caloriecontrolled diet (47). Physical activity is helpful in improving lipid profile by increasing HDL concentration and decreasing both LDL and triglycerides concentrations (56). It is shown to improve insulin resistance and is correlated with lower fasting insulin levels (57). Exercise may result in improvement of endothelial function with reduction in systolic and diastolic BP in addition to its abdominal fat reduction effect (58). Physical activity is also found to have anti-inflammatory effects (59).

\section{Pharmacological therapies}

Medications to treat T2DM, hypertension and dyslipidemia should be initiated as appropriate.

Pharmacological therapy for obesity are becoming increasingly common, particularly among those who do not respond to behavioral therapy alone (60). The US Food and Drug Administration (FDA) has approved pharmacotherapy for children or adolescents with obesity, which is to be considered after a formal program of intensive lifestyle modification has failed to help with weight reduction or for management of comorbidities. High intensity life style modification programs should be continued along with pharmacotherapy $(47,61)$. In general, FDA approved medications used in adults are also approved for adolescents $\geq 16$ years of age with a BMI of $\geq 30$ or $\geq 27 \mathrm{~kg} / \mathrm{m}^{2}$ associated with at least one obesity-related comorbidity (47). Pharmacological therapies should preferably be prescribed by clinicians who are experienced in the use of anti-obesity agents and are aware of the potential for adverse reactions (47). Adolescents who are being treated with anti-obesity medications need to be monitored closely during the therapy course for side effects and weight reduction results. Discontinuation of the medications and reevaluation should be considered in those who are unable to achieve $>4 \% \mathrm{BMI} /$ BMI Z-score reduction following 12 weeks of treatment with the use of medication's full dosage (47). Overall, there is limited evidence in adolescents regarding the safety and efficacy of pharmacological agents specifically in the long term (60). Orlistat (a gastrointestinal lipase inhibitor) is the only obesity medication approved for the use in adolescents over 12 years of age $(47,62)$. Orlistat was approved by the FDA in 2003 (63). By inhibiting gastrointestinal lipase, Orlistat reduces the absorption of triglycerides and cholesterol (64). Known side effects include significant gastrointestinal symptoms and hence it should be taken with meals. Additionally, it can affect the absorption of fat soluble vitamins (64).

Metformin is not FDA approved for obesity but has been used off label to treat childhood obesity (63). It controls hyperglycemia by reducing hepatic glucose production and enhancing tissue insulin sensitivity. Additionally, metformin may have an effect on appetite suppression (65). Gastrointestinal symptoms are the most reported side effects with metformin and generally resolve with time or dose reduction. Lactic acidosis is the most serious adverse event associated with metformin use in adults, although there are no reported cases in children (63). The only reported pediatric lactic acidosis cases resulted from overdose/toxicity in suicidal adolescents $(66,67)$. Gastrointestinal adverse events generally resolve with time or dose reduction. A statistically significant but modest weight loss and BMI reduction effect with short term use 
of metformin combined with life style modifications has been reported. However, there is no clear evidence for long term benefit of metformin use and it is not considered a weight loss medication. It may potentially help prevent weight gain in children and adolescents treated with atypical psychotropic medications (68) and to reduce central obesity in girls with PCOS (69). Additionally, metformin has been reported to be associated with modest reduction in both triglycerides and total cholesterol (63). Sibutramine (a central acting monoamine reuptake inhibitor) (60) was removed from the US market in 2010 due to concerns for cardiovascular safety.

Other weight loss agents used in adults are still under investigation for the use in adolescents. Conjugated linoleic acid (CLA) is thought to be a weight reduction promoting agent, however based on meta-analysis by Onakpoya and colleagues, there is no evidence to support that CLA intake has any clinically relevant effects on body composition over long term. It was noticed that CLA has minimal weight loss effects (70). Liraglutide, a glucagon like peptide-1 (GLP-1) analogue has been shown to have positive long-term results in obesity treatment in adults. A small trial done using another GLP-1 agent (exenatide) showed potential efficacy and safety in management of severe adolescent obesity (71).

\section{Bariatric surgery}

Bariatric surgery can result in significant short-term weight loss in obese children and adolescents (72). It is suggested that surgical intervention for obesity in adolescents be considered only for those who have either completed or almost completed their growth and have completed pubertal development. Bariatric surgery is recommended only if $\mathrm{BMI}$ is $>40 \mathrm{~kg} / \mathrm{m}^{2}$ when mild weight related comorbidities are present or at $>35 \mathrm{~kg} / \mathrm{m}^{2}$ if associated with significant and extreme comorbidities. Extreme comorbidities include T2DM, moderate to severe sleep apnea, pseudotumor cerebri, debilitating orthopedic problems, and NASH with advanced fibrosis (47). Mild comorbidities include hypertension, dyslipidemia, moderate orthopedic problems, mild sleep apnea, NASH, and obesity related extreme psychological distress (73).

Surgical options may be considered without a preceding pharmacological intervention trial, only if a formal life style modification program with documented compliance has failed. Surgical candidates should be evaluated for family unit stability and competency and to exclude any underlying psychiatric illnesses prior to proceeding with surgery. Furthermore, the patient should have an access to an experienced surgeon in a pediatric bariatric surgery center that provides the necessary infrastructure for patient's care, including a team capable of long term follow-up of the metabolic and psychosocial needs of the patient and the family (47). Bariatric surgeries are contraindicated in preadolescents, pregnant and breastfeeding adolescents and those who are planning to get pregnant within the following 2 years. Additionally, surgical management is contraindicated in patients with unresolved substance abuse, eating disorder or any other underlying untreated psychiatric illnesses. All candidates should undergo psychological evaluation before surgery and in the perioperative period (74).

Surgical options include restrictive, malabsorptive or combination procedures (47). Laparoscopic adjustable gastric banding (LAGB) is an example of a restrictive procedure but is not preferred anymore given the high risk of re-operation and the long-term complication rates $(47,75)$. Vertical sleeve gastrectomy (VSG) is another example of a restrictive procedure during which $85 \%$ of the stomach is resected, removing the fundus and greater curvature, leaving a narrow gastric remnant. VGS is becoming more popular given it has fewer complications and side effects than malabsorptive procedures $(75,76)$.

Malabsorptive status is achieved by changing the intestinal anatomy which affects nutrients absorption through the intestinal mucosa. Roux-en- $Y$ gastric bypass (RYGB) is an example of an approach in which gastrectomy provides a restrictive function, while bypassing most of the stomach creates a malabsorptive state and dumping syndrome (47). In a meta-analysis done by Black and colleagues, there was a significant change in the BMI at one year following bariatric surgery with the largest reduction in BMI noticed with RYGB (72). There is some evidence to suggest that bariatric surgery can lead to resolution of associated co-morbidities such as sleep apnea, type 2 diabetes and other cardiovascular risk factors $(77,78)$. Bariatric surgery has also been reported to improve insulin sensitivity and secretion (79). However, RYBG has an increased risk for vitamin $\mathrm{D}$, calcium, and phosphorus malabsorption. Therefore, patients should be monitored for loss of bone mineral density (80). It is recommended that all patients receive daily multivitamins due to the increased risk for multiple vitamin and minerals deficiencies (76).

\section{Conclusions}

Metabolic syndrome is a serious disorder associated with 
multiple diseased states. The definition and criteria for metabolic syndrome in childhood and adolescence remains uncertain at this time. Obesity in childhood is a risk for metabolic syndrome later in life and early intervention may help attenuate the disease process. It would be prudent for clinicians to identify at-risk patients and provide guidance on prevention and management of this disease. Further research is needed to gain a better understanding of this syndrome.

\section{Acknowledgements}

The authors would like to acknowledge Dr. Carol Foster, Division of Pediatric Endocrinology and Diabetes, University of Utah, for her suggestions and comments.

\section{Footnote}

Conflicts of Interest: The authors have no conflicts of interest to declare.

\section{References}

1. Ogden CL, Carroll MD, Lawman HG, et al. Trends in Obesity Prevalence Among Children and Adolescents in the United States, 1988-1994 Through 2013-2014. JAMA 2016;315:2292-9.

2. Flegal KM, Carroll MD, Kit BK, et al. Prevalence of obesity and trends in the distribution of body mass index among US adults, 1999-2010. JAMA 2012;307:491-7.

3. Morrison JA, Friedman LA, Gray-McGuire C. Metabolic syndrome in childhood predicts adult cardiovascular disease 25 years later: the Princeton Lipid Research Clinics Follow-up Study. Pediatrics 2007;120:340-5.

4. Morrison JA, Friedman LA, Wang P, et al. Metabolic syndrome in childhood predicts adult metabolic syndrome and type 2 diabetes mellitus 25 to 30 years later. J Pediatr 2008;152:201-6.

5. Wu YE, Zhang CL, Zhen Q. Metabolic syndrome in children (Review). Exp Ther Med 2016;12:2390-4.

6. Kaur J. A comprehensive review on metabolic syndrome. Cardiol Res Pract 2014;2014:943162.

7. Kylin E. Studien ueber das Hypertonie-Hyperglyca "mie-Hyperurika" miesyndrom. Zentralblatt fuer Innere Medizin 1923;44:105-27.

8. Vague J. Sexual Differentiation, a Factor Affecting the Forms of Obesity. La Presse Médicale 1947;55:339-40.

9. Avogaro P, Crepaldi G. Essential hyperlipidemia, obesity and diabetes. Diabetologia 1965;1:137.

10. Reaven GM. Banting lecture 1988. Role of insulin resistance in human disease. Diabetes 1988;37:1595-607.

11. Kaplan NM. The deadly quartet. Upper-body obesity, glucose intolerance, hypertriglyceridemia, and hypertension. Arch Intern Med 1989;149:1514-20.

12. Haffner SM, Valdez RA, Hazuda HP, et al. Prospective analysis of the insulin-resistance syndrome (syndrome $\mathrm{X}$ ). Diabetes 1992;41:715-22.

13. Magge SN, Goodman E, Armstrong SC. The Metabolic Syndrome in Children and Adolescents: Shifting the Focus to Cardiometabolic Risk Factor Clustering. Pediatrics 2017. [Epub ahead of print]

14. Wittcopp C, Conroy R. Metabolic Syndrome in Children and Adolescents. Pediatr Rev 2016;37:193-202.

15. Alberti KG, Eckel RH, Grundy SM, et al. Harmonizing the metabolic syndrome: a joint interim statement of the International Diabetes Federation Task Force on Epidemiology and Prevention; National Heart, Lung, and Blood Institute; American Heart Association; World Heart Federation; International Atherosclerosis Society; and International Association for the Study of Obesity. Circulation 2009;120:1640-5.

16. Weiss R, Bremer AA, Lustig RH. What is metabolic syndrome, and why are children getting it? Ann N Y Acad Sci 2013;1281:123-40.

17. Ford ES, Li C. Defining the metabolic syndrome in children and adolescents: will the real definition please stand up? J Pediatr 2008;152:160-4.

18. Cook S, Weitzman M, Auinger P, et al. Prevalence of a metabolic syndrome phenotype in adolescents: findings from the third National Health and Nutrition Examination Survey, 1988-1994. Arch Pediatr Adolesc Med 2003;157:821-7.

19. de Ferranti SD, Gauvreau K, Ludwig DS, et al. Prevalence of the metabolic syndrome in American adolescents: findings from the Third National Health and Nutrition Examination Survey. Circulation 2004;110:2494-7.

20. Alberti KG, Zimmet P, Shaw J. Metabolic syndrome-a new world-wide definition. A Consensus Statement from the International Diabetes Federation. Diabet Med 2006;23:469-80.

21. Grundy SM, Cleeman JI, Daniels SR, et al. Diagnosis and management of the metabolic syndrome: an American Heart Association/National Heart, Lung, and Blood Institute Scientific Statement. Circulation 2005;112:2735-52.

22. Agudelo GM, Bedoya G, Estrada A, et al. Variations in the 
prevalence of metabolic syndrome in adolescents according to different criteria used for diagnosis: which definition should be chosen for this age group? Metab Syndr Relat Disord 2014;12:202-9.

23. Friend A, Craig L, Turner S. The prevalence of metabolic syndrome in children: a systematic review of the literature. Metab Syndr Relat Disord 2013;11:71-80.

24. Silveira LS, Buonani C, Monteiro PA, et al. Metabolic Syndrome: Criteria for Diagnosing in Children and Adolescents. Endocrinol Metab Synd 2013;2:118.

25. Hadjiyannakis $S$. The metabolic syndrome in children and adolescents. Paediatr Child Health 2005;10:41-7.

26. Zimmet PZ, McCarty DJ, de Courten MP. The global epidemiology of non-insulin-dependent diabetes mellitus and the metabolic syndrome. J Diabetes Complications 1997;11:60-8.

27. D'Adamo E, Santoro N, Caprio S. Metabolic syndrome in pediatrics: old concepts revised, new concepts discussed. Curr Probl Pediatr Adolesc Health Care 2013;43:114-23.

28. Meshkani R, Adeli K. Hepatic insulin resistance, metabolic syndrome and cardiovascular disease. Clin Biochem 2009;42:1331-46.

29. Natali A, Ferrannini E. Hypertension, insulin resistance, and the metabolic syndrome. Endocrinol Metab Clin North Am 2004;33:417-29.

30. Balletshofer BM, Rittig K, Enderle MD, et al. Endothelial dysfunction is detectable in young normotensive first-degree relatives of subjects with type 2 diabetes in association with insulin resistance. Circulation 2000;101:1780-4.

31. Weiss R, Dziura J, Burgert TS, et al. Obesity and the metabolic syndrome in children and adolescents. N Engl J Med 2004;350:2362-74.

32. Fernandez JR, Redden DT, Pietrobelli A, et al. Waist circumference percentiles in nationally representative samples of African-American, European-American, and Mexican-American children and adolescents. J Pediatr 2004;145:439-44.

33. Janssen I, Katzmarzyk PT, Srinivasan SR, et al. Combined influence of body mass index and waist circumference on coronary artery disease risk factors among children and adolescents. Pediatrics 2005;115:1623-30.

34. Brambilla P, Bedogni G, Moreno LA, et al. Crossvalidation of anthropometry against magnetic resonance imaging for the assessment of visceral and subcutaneous adipose tissue in children. Int J Obes (Lond) 2006;30:23-30.

35. Khoury M, Manlhiot C, McCrindle BW. Role of the waist/height ratio in the cardiometabolic risk assessment of children classified by body mass index. J Am Coll Cardiol 2013;62:742-51.

36. Burns SF, Lee SJ, Arslanian SA. Surrogate lipid markers for small dense low-density lipoprotein particles in overweight youth. J Pediatr 2012;161:991-6.

37. Standards of Medical Care in Diabetes-2017: Summary of Revisions. Diabetes Care 2017;40:S4-5.

38. Mencin AA, Lavine JE. Nonalcoholic fatty liver disease in children. Curr Opin Clin Nutr Metab Care 2011;14:151-7.

39. Coviello AD, Legro RS, Dunaif A. Adolescent girls with polycystic ovary syndrome have an increased risk of the metabolic syndrome associated with increasing androgen levels independent of obesity and insulin resistance. J Clin Endocrinol Metab 2006;91:492-7.

40. Korner A, Kratzsch J, Gausche R, et al. New predictors of the metabolic syndrome in children--role of adipocytokines. Pediatr Res 2007;61:640-5.

41. Oliveira AC, Oliveira AM, Adan LF, et al. C-reactive protein and metabolic syndrome in youth: a strong relationship? Obesity (Silver Spring) 2008;16:1094-8.

42. Barlow SE. Expert committee recommendations regarding the prevention, assessment, and treatment of child and adolescent overweight and obesity: summary report. Pediatrics 2007;120 Suppl 4:S164-92.

43. Temple JL, Cordero P, Li J, et al. A Guide to NonAlcoholic Fatty Liver Disease in Childhood and Adolescence. Int J Mol Sci 2016;17(6).

44. Expert Panel on Integrated Guidelines for Cardiovascular Health and Risk Reduction in Children and Adolescents; National Heart, Lung, and Blood Institute. Expert panel on integrated guidelines for cardiovascular health and risk reduction in children and adolescents: summary report. Pediatrics 2011;128 Suppl 5:S213-56.

45. James J, Thomas P, Cavan D, et al. Preventing childhood obesity by reducing consumption of carbonated drinks: cluster randomised controlled trial. BMJ 2004;328:1237.

46. Pereira MA, Ludwig DS. Dietary fiber and body-weight regulation. Observations and mechanisms. Pediatr Clin North Am 2001;48:969-80.

47. Styne DM, Arslanian SA, Connor EL, et al. Pediatric Obesity-Assessment, Treatment, and Prevention: An Endocrine Society Clinical Practice Guideline. J Clin Endocrinol Metab 2017;102:709-57.

48. Committee on Nutrition. American Academy of Pediatrics: The use and misuse of fruit juice in pediatrics. Pediatrics 2001;107:1210-3.

49. Shefferly A, Scharf RJ, DeBoer MD. Longitudinal 
evaluation of $100 \%$ fruit juice consumption on BMI status in 2-5-year-old children. Pediatr Obes 2016;11:221-7.

50. Kamath CC, Vickers KS, Ehrlich A, et al. Clinical review: behavioral interventions to prevent childhood obesity: a systematic review and metaanalyses of randomized trials. J Clin Endocrinol Metab 2008;93:4606-15.

51. McGovern L, Johnson JN, Paulo R, et al. Clinical review: treatment of pediatric obesity: a systematic review and meta-analysis of randomized trials. J Clin Endocrinol Metab 2008;93:4600-5.

52. Hoelscher DM, Kirk S, Ritchie L, et al. Position of the Academy of Nutrition and Dietetics: interventions for the prevention and treatment of pediatric overweight and obesity. J Acad Nutr Diet 2013;113:1375-94.

53. Rajjo T, Mohammed K, Alsawas M, et al. Treatment of Pediatric Obesity: An Umbrella Systematic Review. J Clin Endocrinol Metab 2017;102:763-75.

54. Rhodes ET, Ludwig DS. Childhood obesity as a chronic disease: keeping the weight off. JAMA 2007;298:1695-6.

55. Gow ML, Ho M, Burrows TL, et al. Impact of dietary macronutrient distribution on BMI and cardiometabolic outcomes in overweight and obese children and adolescents: a systematic review. Nutr Rev 2014;72:453-70.

56. Bremer AA, Auinger P, Byrd RS. Relationship between insulin resistance-associated metabolic parameters and anthropometric measurements with sugar-sweetened beverage intake and physical activity levels in US adolescents: findings from the 1999-2004 National Health and Nutrition Examination Survey. Arch Pediatr Adolesc Med 2009;163:328-35.

57. Schmitz KH, Jacobs DR Jr, Hong CP, et al. Association of physical activity with insulin sensitivity in children. Int J Obes Relat Metab Disord 2002;26:1310-6.

58. Farpour-Lambert NJ, Aggoun Y, Marchand LM, et al. Physical activity reduces systemic blood pressure and improves early markers of atherosclerosis in pre-pubertal obese children. J Am Coll Cardiol 2009;54:2396-406.

59. Rubin DA, Hackney AC. Inflammatory cytokines and metabolic risk factors during growth and maturation: influence of physical activity. Med Sport Sci 2010;55:43-55.

60. Czernichow S, Lee CM, Barzi F, et al. Efficacy of weight loss drugs on obesity and cardiovascular risk factors in obese adolescents: a meta-analysis of randomized controlled trials. Obes Rev 2010;11:150-8.

61. Sherafat-Kazemzadeh R, Yanovski SZ, Yanovski JA. Pharmacotherapy for childhood obesity: present and future prospects. Int J Obes (Lond) 2013;37:1-15.

62. Maahs D, de Serna DG, Kolotkin RL, et al. Randomized, double-blind, placebo-controlled trial of orlistat for weight loss in adolescents. Endocr Pract 2006;12:18-28.

63. McDonagh MS, Selph S, Ozpinar A, et al. Systematic review of the benefits and risks of metformin in treating obesity in children aged 18 years and younger. JAMA Pediatr 2014;168:178-84.

64. McDuffie JR, Calis KA, Uwaifo GI, et al. Three-month tolerability of orlistat in adolescents with obesity-related comorbid conditions. Obes Res 2002;10:642-50.

65. Adeyemo MA, McDuffie JR, Kozlosky M, et al. Effects of metformin on energy intake and satiety in obese children. Diabetes Obes Metab 2015;17:363-70.

66. Bebarta VS, Pead J, Varney SM. Lacticemia After Acute Overdose of Metformin in an Adolescent Managed Without Intravenous Sodium Bicarbonate or Extracorporeal Therapy. Pediatr Emerg Care 2015;31:589-90.

67. McNamara K, Isbister GK. Hyperlactataemia and clinical severity of acute metformin overdose. Intern Med J 2015;45:402-8.

68. Klein DJ, Cottingham EM, Sorter M, et al. A randomized, double-blind, placebo-controlled trial of metformin treatment of weight gain associated with initiation of atypical antipsychotic therapy in children and adolescents. Am J Psychiatry 2006;163:2072-9.

69. Hoeger K, Davidson K, Kochman L, et al. The impact of metformin, oral contraceptives, and lifestyle modification on polycystic ovary syndrome in obese adolescent women in two randomized, placebo-controlled clinical trials. J Clin Endocrinol Metab 2008;93:4299-306.

70. Onakpoya IJ, Posadzki PP, Watson LK, et al. The efficacy of long-term conjugated linoleic acid (CLA) supplementation on body composition in overweight and obese individuals: a systematic review and meta-analysis of randomized clinical trials. Eur J Nutr 2012;51:127-34.

71. Kelly AS, Rudser KD, Nathan BM, et al. The effect of glucagon-like peptide-1 receptor agonist therapy on body mass index in adolescents with severe obesity: a randomized, placebo-controlled, clinical trial. JAMA Pediatr 2013;167:355-60.

72. Black JA, White B, Viner RM, et al. Bariatric surgery for obese children and adolescents: a systematic review and meta-analysis. Obes Rev 2013;14:634-44.

73. Nobili V, Vajro P, Dezsofi A, et al. Indications and limitations of bariatric intervention in severely obese children and adolescents with and without nonalcoholic steatohepatitis: ESPGHAN Hepatology Committee Position Statement. J Pediatr Gastroenterol Nutr 
2015;60:550-61.

74. Hsia DS, Fallon SC, Brandt ML. Adolescent bariatric surgery. Arch Pediatr Adolesc Med 2012;166:757-66.

75. Barnett SJ. Surgical management of adolescent obesity. Adv Pediatr 2013;60:311-25.

76. Wasserman H, Inge TH. Bariatric surgery in obese adolescents: opportunities and challenges. Pediatr Ann 2014;43:e230-6.

77. Inge TH, Miyano G, Bean J, et al. Reversal of type 2 diabetes mellitus and improvements in cardiovascular risk factors after surgical weight loss in adolescents. Pediatrics
2009; 123:214-22

78. Kalra M, Inge T. Effect of bariatric surgery on obstructive sleep apnoea in adolescents. Paediatr Respir Rev 2006;7:260-7.

79. Inge TH, Prigeon RL, Elder DA, et al. Insulin Sensitivity and beta-Cell Function Improve after Gastric Bypass in Severely Obese Adolescents. J Pediatr 2015;167:1042-8.e1.

80. Kaulfers AM, Bean JA, Inge TH, et al. Bone loss in adolescents after bariatric surgery. Pediatrics 2011;127:e956-61.

Cite this article as: Al-Hamad D, Raman V. Metabolic syndrome in children and adolescents. Transl Pediatr 2017;6(4):397-407. doi: 10.21037/tp.2017.10.02 